\title{
Syntaxin-3 and syntaxin-1A inhibit L-type calcium channel activity, insulin biosynthesis and exocytosis in beta-cell lines
}

\author{
Y.Kang ${ }^{1}$, X.Huang ${ }^{1}$, E. A. Pasyk ${ }^{1}$, J.Ji ${ }^{1}$, G. G.Holz ${ }^{2}$, M. B. Wheeler ${ }^{1}$, R. G. Tsushima ${ }^{1}$, H. Y. Gaisano ${ }^{1}$ \\ ${ }^{1}$ Departments of Medicine and Physiology, University of Toronto, Toronto, Ontario, Canada \\ ${ }^{2}$ Department of Physiology and Neuroscience, New York University, New York, USA
}

\section{Abstract}

Aims/hypothesis. Syntaxin-1A (Syn-1A) is known to play a negative regulatory role in insulin secretion but the precise mechanisms for its action are not clear. Syn-2, -3 and -4 are also present in islet beta cells but their functions are not known. Here, we investigated the role of these syntaxins in the insulin secretory process.

Methods. We examined the following effects of Syn-1, $-2,-3$ and -4 expression in insulinoma beta-cell lines. Endogenous insulin secretion was measured by batch radioimmunoassay (RIA) and single cell patch clamp capacitance measurements. The $\mathrm{L}$-type $\mathrm{Ca}^{2+}$ channel activity was studied by patch clamp electrophysiology. Insulin gene transcription was examined by Northern blotting and measurement of insulin gene promoter activity by the co-expression of cyan fluorescent protein-labelled rat insulin promoter.

Results. Syn-1A or -3 , but not Syn- 2 or -4 overexpression, inhibited $\mathrm{K}^{+}$-induced insulin release as determined by RIA $(49.7 \pm 5.5 \%$ and $49.1 \pm 6.2 \%$, respectively) and electrophysiologic membrane capaci- tance measurements $(68.0 \pm 21.0 \%$ and $58.0 \pm$ $13.2 \%$, respectively). Overexpressed Syn-1A and -3 , but not Syn-2, inhibited $\mathrm{Ca}^{2+}$ channel current amplitude by $39.5 \pm 11.6 \%$ and $52.7 \pm 6.0 \%$, respectively. Of note, overexpression of Syn-1A and -3 also reduced single cell (by confocal microscopy) and total cellular endogenous insulin content (by RIA) by $24.8 \pm 4.2 \%$ and $31.8 \pm 3.9 \%$, respectively. This correlated to a reduction in endogenous insulin mRNA by $24.5 \pm 4.2 \%$ and $25.7 \pm 4.2 \%$, respectively. This inhibition of insulin biosynthesis is mainly at the level of insulin gene transcription as demonstrated by an inhibition of insulin gene promoter activity (53.3 \pm $9.15 \%$ and $39.0 \pm 6.8 \%$, respectively).

Conclusions/interpretation. These results demonstrate that Syn-1A and -3 possess strong inhibitory actions on both insulin exocytosis and insulin biosynthesis whereas Syn-2 and -4 do not inhibit the insulin secretory process. [Diabetologia (2002) 45: 231-241]

Keywords Syntaxin, insulin secretion, SNAREs, insulin biosynthesis, voltage-dependent $\mathrm{Ca}^{2+}$ channels.
Received: 10 July 2001 and in revised form: 1 October 2001

Corresponding author: H. Y. Gaisano, Departments of Medicine and Physiology, Room 7226 Medical Sciences Building, University of Toronto, Toronto, Ontario, Canada M5S 1A8, e-mail: herbert.gaisano@utoronto.ca

Abbreviations: Syn, Syntaxin; SNAP-25, synaptosomal-associated protein of $25 \mathrm{kDa}$; VAMP-2, vesicle-associated membrane protein-2; NSF, N-ethylmaleimade-sensitive fusion pro- tein; SNARE, soluble NSF attachment protein receptor; ECFP, enhanced cyan fluorescent protein; EYFP, enhanced yellow fluorescent protein; RIP-2, rat insulin-2 promoter; VDCC, voltage-dependent $\mathrm{Ca}^{2+}$ channels; RT-PCR, reverse transcription-coupled polymerase chain reaction; BoNT, botulinum neurotoxin; SDS-PAGE, sodium dodecyl sulfate-polyacrylamide gel electrophoresis; KRBB, Krebs-Ringer bicarbonate buffer; SSC, saline-sodium citrate buffer 
The basic components of the insulin exocytotic machinery of pancreatic islet beta cells, collectively called SNARE (soluble NSF attachment protein receptor) proteins resemble those which mediate neurotransmitter release. $[1,2]$. According to the current view of SNARE-mediated vesicle fusion, including exocytosis, SNARE proteins on the donor vesicle (vSNARE VAMP-2 in islet beta cells and neurons) and the target membrane (t-SNAREs, SNAP-25 and syntaxin-1A in islet beta cells and neurons) interact to form a stable complex which provides the energy for membrane fusion [3]. Immunoprecipitation of this SNARE complex has identified the docked readily-releasable granule pool which is responsible for the first phase of glucose-stimulated insulin secretion [4]. The role of these SNARE proteins in vesicle fusion in neurons is well established, but the $\mathrm{v}$ SNARE, VAMP-2, has been shown to be involved in synaptic vesicle biogenesis from endosomes [5]. The t-SNAREs, syntaxin-1A (Syn-1A) and SNAP-25, are capable of binding neuronal and islet beta-cell calcium channels $[6,7,8]$ to further regulate the secretory process. SNAP-25 is also involved in axonal growth [9]. Many isoforms of the original SNARE proteins mediating regulated exocytotic fusion have been identified and found to be involved in other vesicle transport and membrane fusion processes of neuronal and non-neuronal cells [10]. However, the functions of the vast majority of these non-neuronal SNARE isoforms are not known.

The precise mechanisms of the dysregulation of insulin secretion and insulin biosynthesis in Type-II (non-insulin-dependent) diabetes mellitus are not known [11]. Recent studies in obese $f a / f a$ Zucker rat [12] and non-obese GK rat [13] models of obesity and Type-II diabetes respectively, which showed reduced glucose-stimulated insulin release, found the expression of SNARE proteins to be reduced to a similar extent. Of note, increased expression by adenoviral infection of SNAP-25 or Syn-1A to normal concentrations in the GK rats, resulted in partial recovery of glucose-mediated insulin secretion [13]. This diminished expression of exocytotic SNARE proteins could be related to the chronic hyperglycaemia-induced loss of islet beta-cell differentiation resulting in an inhibition of gene expression of the components of glucose-mediated secretory pathway [14]. In contrast, short-term glucose stimulation up regulates islet beta-cell insulin biosynthesis and Syn-1A concentrations [15]. This could be a mechanism to increase the concentrations of exocytotic proteins necessary to improve secretion [15]. Glucose is capable of short-term up regulation of insulin gene transcription [16]. Taken together, these studies show that short-term and long-term glucose stimulation provide distinct forward or downstream regulation of insulin secretory components. A more recent report showed that glucose-induced increases in insulin gene tran- scription are largely due to the secreted insulin itself, and so provide autocrine regulation [17]. Consistent with this, we hypothesized that the SNARE proteins could provide additional feedback regulation of insulin biosynthesis. This would provide a mechanism whereby the most proximal signal, which is glucose stimulation, and distal, secretory components, including SNARE proteins and insulin, could be intricately related to control insulin exocytosis and biosynthesis. A pathologic regulation of these processes in Type II diabetes might then contribute to the abnormal glucose-mediated insulin secretory responses.

Syntaxin is perhaps the most fascinating SNARE because the coiled-coil domains within this protein are capable of interacting with a large number of proteins besides cognate SNAREs and $\mathrm{Ca}^{2+}$ channels $[18,19,20]$. Neuronal Syn-1A, the best studied syntaxin, has also been shown to bind synaptotagmins, Munc13 and Munc18, cysteine-string proteins, complexins, and ion channels other than $\mathrm{Ca}^{2+}$ channels (i.e. CFTR) $[18,19,20]$. Syntaxin belongs to a large gene family, but the functions of the vast majority of the isoforms are not known [10, 21]. Syn-1, $-2,-3$ and -4 are known to be the exocytic SNARE proteins [21]. Syn-4 is well established to mediate GLUT-4 exocytosis in adipocytes and muscle cells [22, 23]. Syn-3 mediates apical exocytosis in a number of non-neuronal epithelial cells [24, 25]. These syntaxins are also endogenous proteins in pancreatic islets and several beta-cell lines [26, 27] whose actions are not known, but might possess distinct or redundant functions to Syn-1A. Supporting this, in islet beta cells, isoforms within the VAMP (VAMP-2 and VAMP-3) [28] and SNAP-25 (SNAP-25 and SNAP-23) [29] families have been shown to have redundant functions.

In this study, we explored the functional role of four plasma membrane-bound isoforms of the syntaxin family (Syn-1, -2, -3 and -4) in insulin secretion and biosynthesis. These syntaxins were transiently overexpressed in the insulinoma cells. We found that overexpressed Syn-1A and Syn-3, but not Syn-2 or-4, uniformly inhibited stimulated insulin secretion as determined by radioimmunoassay and patch clamp capacitance, and reduced L-type $\mathrm{Ca}^{2+}$ channel activity. Remarkably, we also found that this inhibition was contributed by Syn-1A and Syn-3 on insulin biosynthesis at the level of insulin gene transcription step.

\section{Materials and methods}

Materials. HIT-T15 cells were kindly provided by R. Santerre (Eli Lilly, Indianapolis, Ind., USA), INS-1 cell line by Claes Wollheim (University Medical Center, Geneva, Switzerland), and $\beta$ TC6-f7 cell line by S. Efrat (Albert Einstein College of Medicine, Bronx, N. Y., USA). Mouse monoclonal antibody 
Table 1. Oligonucleotide primers used in this study

\begin{tabular}{llllll}
\hline & Position & Sense sequence (5'-3') & Position & Antisense sequence (5'-3') & length (bp) \\
\hline Syn 1 A & $1-22^{\text {a }}$ & ATGAAGGACCGAACCCAGGAGC & $868-847$ & TCTATCCAAAGATGCCCCCGA & 868 \\
Syn 2 & $1-19$ & ATGCGGGACCGGCTGCCGG & $873-852$ & TCATTTGCCAACCGTCAAGCC & 873 \\
Syn 3 & $1-21$ & ATGAAGGACCGACTGGAGCAG & $870-847$ & TTATTTCAGCCCAACGGACAATC & 870 \\
Syn 4 & $1-21$ & ATGCGCGACAGGACCCATGAG & $891-869$ & TTATCCAACGGTTATGGTGATG & 891
\end{tabular}

${ }^{a}$ Positions of the primers are numbered from the ATG initiation codon of the rat syntaxin cDNA sequences reported by Bennett et al. (21)

against HPC-1 (Syn-1A) was purchased from Sigma (St. Louis, Mo., USA), against actin from Boehringer Mannheim (Laval, Quebec, Canada), and against SNAP-25 from Sternberger Monoclonals Inc. (Baltimore, Md., USA). Rabbit anti-Syn-2 and Syn-3 polyclonal antibodies were a generous gift from $\mathrm{M}$. Bennett (University of California, Berkeley, Calif., USA), and sheep anti Syn-4 antibody was kindly provided by J. Pessin (University of Iowa, Iowa, USA). Guinea pig anti-insulin antibody was a gift from R. Pederson (University of British Columbia, British Columbia, Canada), and rabbit anti-L type $(\alpha 1 C)$ from antibody was from Alomone Labs (Jerusalem, Israel). The polyclonal rabbit antibody against Aequerea victoria green fluorescent protein, recognising cyan fluorescent protein (CFP), was obtained from Clontech Laboratories (Palo Alto, Calif., USA). All other reagents used were of the highest quality commercially available.

Generation of expression plasmids. The total RNA used for reverse transcription was isolated from mouse $\beta$ TC6-f7 cells with Trizol reagent (GIBCO BRL, Gaithersburg, Md., USA) following the manufacturer's instructions. The full coding regions of Syn-1A through -4 were obtained by reverse transcriptioncoupled PCR (RT-PCR) according to manufacturer's instructions and using oligonucleotide primers to the published rat sequences [21], as listed in Table 1. Following cloning into PCR2.1 (Invitrogen, Groningen, The Netherlands), amplification products were verified by dideoxy sequencing with $\mathrm{T}_{7}$ polymerase and then subcloned into pcDNA3 (Invitrogen) for overexpression of syntaxin proteins. For the generation of plasmid RIP-ECFP, 700 bp of the rat insulin-2 promoter (RIP2) was cloned into the vector pd2EYFP-1 (enhanced yellow fluorescent protein) (Clontech, Palo Alto, Calif., USA) at a Bam $\mathrm{H} 1$ site. YFP was replaced with enhanced cyan fluorescent protein (ECFP) from pECFP-C2 (Clontech) using Age1 and Not 1 restriction sites.

\section{Transfection and Insulin Secretion:}

Transfection. Transfection of HIT-T15 and INS-1 cells and the stimulation of insulin secretion were carried out as previously described [30]. Briefly, HIT-T15 cells were grown in an atmosphere of $5 \% \mathrm{CO}_{2} / 95 \%$ air in RPMI 1640 medium (GIBCO BRL, Calif., USA) containing $4.5 \mathrm{~g} / 1$ glucose and supplemented with $10 \%$ fetal calf serum (Cansera, Rexdale, Ont., Canada). For transfection, the cells were plated at a density of $1.8 \cdot 10^{5} /$ well in a 24 -well plate. After $20-24 \mathrm{~h}$ of incubation (reaching about $60-80 \%$ confluence), the cells were transfected with $0.5 \mu \mathrm{g}$ DNA/well in a 24-well plate format using Lipofectamine reagent (GIBCO BRL) according to manufacturer's instructions. For co-transfection, half the amount of each cDNA was used. Transfection efficiency was determined using either pcDNA3/His/LacZ (Invitrogen) or $\mathrm{pEGFP/pECFP}$ (Clontech) as control plasmids. Overexpression of the syntaxin protein isoforms was confirmed by Western blot analysis and confocal immunofluorescence microscopy.
Insulin secretion. Two days after transfection, the cells were washed and then incubated in $0.5 \mathrm{ml}$ low $\mathrm{K}^{+}$-Krebs-Ringer bicarbonate (KRB) buffer (in mmol/l, $4.8 \mathrm{KCl}, 129 \mathrm{NaCl}, 5 \mathrm{NaH}-$ $\mathrm{CO}_{3}, 1.2 \mathrm{KH}_{2} \mathrm{PO}_{4}, 1 \mathrm{CaCl}_{2}, 1.2 \mathrm{MgSO}_{4}, 0.5$ glucose and 10 HEPES, pH 7.4) for 30 mins. For $\mathrm{K}^{+}$stimulation studies, the media was then exchanged with $0.5 \mathrm{ml}$ of the same buffer containing either low $\mathrm{K}^{+}(4.8 \mathrm{mmol} / \mathrm{K} \mathrm{KCl}$ for basal secretion) or high $\mathrm{K}^{+}(30 \mathrm{mmol} / \mathrm{K} \mathrm{KCl})$. At the end of incubation for $1 \mathrm{~h}$, the media was collected and centrifuged at $3000 \mathrm{~g}$ for $3 \mathrm{~min}$ to remove detached cells. The resulting upper half of the supernatants was collected and determined for insulin released by radioimmunoassay according to manufacturer's instructions (Linco, St. Charles, Mo., USA). To determine cellular insulin content, the remaining supernatant was removed and $0.5 \mathrm{ml}$ $1 \mathrm{~mol} / \mathrm{l}$ acetic acid $/ 0.1 \%$ BSA was added to each well. The cells were then scraped from the wells, lysed by two 2 freeze-thaw cycles, and spun down. The resulting supernatant was then diluted with $0.2 \mathrm{~mol} / 1$ glycine $/ 0.25 \%$ BSA buffer $(\mathrm{pH} 8.8)$ for insulin assay. The cell protein concentration for each well was also determined, and insulin values were normalized to the protein concentration. Data for stimulated release presented are always expressed as the values over basal release, which is $\mathrm{K}^{+}$-induced release minus basal release. Stimulated release was typically 1-3 times basal release.

Patch clamp and capacitance measurements. The beta-cell lines, HIT-T15 and INS-1, were studied under standard whole-cell patch clamp conditions [31]. To identify the Syn$1 \mathrm{~A},-2,-3$ or -4 transfected INS-1 cells, we co-expressed the pEGFP [30]. For cell capacitance measurements, the intracellular solution contained (in mmol/l) $140 \mathrm{KCl}, 10 \mathrm{HEPES}, 1$ EGTA, $1 \mathrm{MgCl}_{2}$ and $3 \mathrm{MgATP}$, pH 7.3 with $\mathrm{KOH}$. Extracellular solution contained (in mmol/l) $140 \mathrm{NaCl}, 4 \mathrm{KCl}, 1 \mathrm{MgCl}_{2}$, $2 \mathrm{CaCl}_{2}$ and $10 \mathrm{HEPES}, \mathrm{pH} 7.3$ with $\mathrm{NaOH}$. Experiments were done at room temperature (room temperature, $\left.22-34{ }^{\circ} \mathrm{C}\right)$. Capacitance measurements $\left(\mathrm{C}_{\mathrm{m}}\right)$ were then completed similarly [32, 33]. Specifically, the cells were held at $-70 \mathrm{mV}$ and depolarized to $0 \mathrm{mV}$ for $250 \mathrm{~ms}$. Immediately following depolarization, cells were exposed to a sine wave centred at $-70 \mathrm{mV}$, and the changes in $\mathrm{C}_{\mathrm{m}}$ stimulated by this depolarizing voltage pulse were observed. These experiments were done using a quick-response lock-in EPC-9 patch clamp amplifier (HEKA Elektronik, Lambrecht, Germany) and a highspeed and memory computer (PC, Pentium III) running specialized patch clamp Pulse software (HEKA Elektronik, Germany). Using this equipment configuration, very small changes (fF range) in whole cell capacitance were monitored for secretary granule fusion.

The whole-cell patch clamp technique was used to measure L-type $\mathrm{Ca}^{2+}$ channel activity [34]. The extracellular solution contained (in mmol/l): $120 \mathrm{NaCl}, 20 \mathrm{BaCl}_{2}, 20$ tetraethylammonium (TEA) chloride, $5 \mathrm{CsCl}, 1 \mathrm{MgCl}_{2}, 10$ glucose and 10 HEPES ( $\mathrm{pH}$ 7.4). Patch pipette solution consisted of (in mmol/l) 120 CsCl, 20 TEA-Cl, 5 MgATP, 5 EGTA, 5 HEPES (pH 7.2). TEA and Cs were used to block $\mathrm{K}^{+}$currents. Cur- 
rents were recorded using an EPC-9 amplifier and Pulse software with records being digitized at $10 \mathrm{kHz}$ and filtered at 2 $\mathrm{kHz}$ (-3 dB, 4-pole Bessel filter). L-type $\mathrm{Ca}^{2+}$ currents were elicited by $200-\mathrm{ms}$ step pulses from -60 to $+80 \mathrm{mV}$ from a holding potential of $-80 \mathrm{mV}$ at a stimulation frequency of 0.2 $\mathrm{Hz}$. Current traces were electronically compensated for pipette and membrane capacitance and series resistance, and were normalized to cell capacitance $(16.0 \pm 1.2 \mathrm{pF}, n=49)$. Experiments were done at room temperature.

Immunofluorescence microscopy and Western blot analysis. HIT-T15 cells were plated on polylysine-coated coverslips and transfected as described above. These were then rinsed and processed $[26,30]$. The cells were fixed in $2 \%$ formaldehyde for 30 mins at room temperature, blocked with $5 \%$ normal goat serum with $0.1 \%$ saponin for $0.5 \mathrm{~h}$ at room temperature, and then immunolabelled with primary antibodies against Syn-1, $-2,-3,-4$, insulin (guinea pig), overnight at $4{ }^{\circ} \mathrm{C}$. After rinsing with $0.1 \%$ saponin/PBS, the coverslips were then incubated with the appropriate rhodamine-labelled secondary antiserum for $1 \mathrm{~h}$ at room temperature, and then mounted on slides in a fading retarder, $0.1 \% \mathrm{p}$-phenylenediamine in glycerol, and examined using a laser scanning confocal imaging system (Carl Zeiss, Oberkochen, Germany). Transfected cells were identified by co-expression and visualisation with EGFP/EECFP.

To visualise and determine the content of ECFP protein in cells transfected with either a vector containing the ECFP cDNA under the transcriptional control of CMV or RIP2 promoters, fluorescence imaging and Western blot analyses were carried out. ECFP was visualised using an inverted epifluorescence microscope (model IX70, Olympus Optical, Tokyo, Japan) fitted with an imaging system (Merlin, Life Sciences Resources, Olympus Optical, Tokyo, Japan) capable of digitizing the fluorescence signals.

For Western blotting, HIT-T15 cells were washed with phosphate-buffered saline (PBS, pH 7.4) and harvested in sample buffer containing $50 \mathrm{mmol} / \mathrm{l}$ TRIS (pH 6.8), $100 \mathrm{mmol} / \mathrm{l} \mathrm{di}-$ thiothreitol, $2 \%$ sodium dodecyl sulphate (SDS), $10 \%$ glycerol and $0.01 \%$ bromophenol blue. An aliquot of the samples was subjected to protein determination. About $20 \mu \mathrm{g}$ protein was separated on a $15 \%$ SDS-PAGE, and transferred to PVDF membranes (Millipore, Bedford, Mass., USA) and identified with specific primary antibodies against Syn-1A (1:2000 dilution), Syn-2 (1:250), Syn-3 (1:1000), Syn-4 (1:1000), ECFP $(1: 2000)$, actin $(1: 10,000)$ or L-type $\mathrm{Ca}^{2+}$ channel (1:2000). Detection was made possible by enhanced chemiluminescence (Amersham, Arlington Heights, Ill., USA), and the specific bands were quantified by densitometric scanning of the blots.

Northern blot analysis of $m R N A$. Total RNA was isolated from transfected HIT-T15 cells using the same methods as described above. Generation of the Expression Constructs, and electrophoresed on a $1.2 \%$ formaldehyde $/ 1 \%$ agarose gel $(3-4 \mu \mathrm{g}$ RNA/lane), and transferred to nylon membranes (Amersham Pharmacia Biotech, Baie d'Urfé, Québec, Canada). The RNA was fixed to the membrane by UV-crosslinking and hybridized to insulin or human beta-actin probes which were randomly labelled with [ $\left.{ }^{32} \mathrm{P}\right]$-dCTP (3000C/mmol, DuPont-New England Nuclear, Cambridge, Mass., USA) using a random labelling kit (GIBCO BRL). The membranes were prehybridized for $4 \mathrm{~h}$ at $42^{\circ} \mathrm{C}$ in a buffer containing $50 \%$ (vol/vol) deionized formamide, $5 \times$ SSPE (saline-sodium phosphate-EDTA buffer), $2 \times$ Denhardt's reagent and $0.1 \%$ SDS. Hybridization was carried out overnight at $42^{\circ} \mathrm{C}$ in the same buffer containing denatured ${ }^{32} \mathrm{P}$-labelled probes and $100 \mu \mathrm{g} / \mathrm{ml}$ denatured salmon sperm DNA (GIBCO BRL). Filters were then sequentially washed in $2 \times$ saline-sodium citrate buffer (SSC) $/ 0.1 \%$ SDS at room temperature for $2 \times 10 \mathrm{~min}, 0.1 \times \mathrm{SSC} / 0.1 \% \mathrm{SDS}$ at $42^{\circ} \mathrm{C}$ for $40 \mathrm{~min}$, and finally in $2 \mathrm{xSSC}$ at room temperature for $10 \mathrm{~min}$. The mRNA level was quantified by densitometric analysis.

Statistical analysis. The results were analysed using Student's $t$ test for single comparisons and by analysis of variance (ANOVA) for multiple comparisons. They were expressed as means \pm SEM in the graphs shown. A $p$ value of less than 0.05 was considered to be statistically significant.

\section{Results}

Recombinant expression of syntaxins in HIT-T15 cells. Transient transfection of Syn-1A, -2, -3 or -4 cDNA in HIT-T15 cells resulted in increased concentrations of these proteins. Immunoblot analysis of the transfected HIT cell lysates showed at least a threefold increase of these proteins compared to the concentrations in HIT cells transfected with the empty expression vector (control) (Fig.1A). Confocal microscopy of these cells confirmed the uniform targeting and localisation of these overexpressed syntaxins (indicated by arrows) to the plasma membrane (Fig. 1B i, iii, v, and vi), which is the native compartment of the endogenous syntaxins. Overexpression of these syntaxins therefore did not cause an aberrant targeting of these proteins, although in cells expressing very high concentrations of the syntaxins, as with a confocal study of the Syn-1A overexpression, there is also increased staining within the perinuclear region, probably the Golgi. Of note, Syn-3 was the only endogenous syntaxin abundantly present in the cytosol (indicated by arrowheads, Fig.1B iii) which overlaps with the insulin granule staining (Fig, 1B iv). Although the estimation of the concentrations of overexpressed proteins from the immunofluorescence microscopy study is only semi-quantitative, the observed transfection efficiency of $40-50 \%$ taken together with the immunoblot analysis, indicate that the transfected cells expressed at least a sixfold increase in the concentrations of syntaxins compared with the endogenous concentrations of control cells. When double-labelled with anti-insulin antibodies, the cells overexpressing Syn-1 or Syn-3 showed reduced insulin content (indicated by arrows, Fig. 1B ii and iv) when compared to those adjacent cells not overexpressing these syntaxins. Syn-2 or Syn-4 had no effect on cellular insulin content (data not shown).

\section{Effects of overexpression of syntaxins on endogenous insulin in HIT-T15 cells. $\mathrm{Ca}^{2+}$-induced insulin secre- tion was first examined by high $\mathrm{K}^{+}$-induced mem- brane depolarization and by glucose stimulation [35]. The effects of overexpressed Syn-1A, $-2,-3$, or -4 on $\mathrm{K}^{+}$-induced secretion of endogenous insulin}




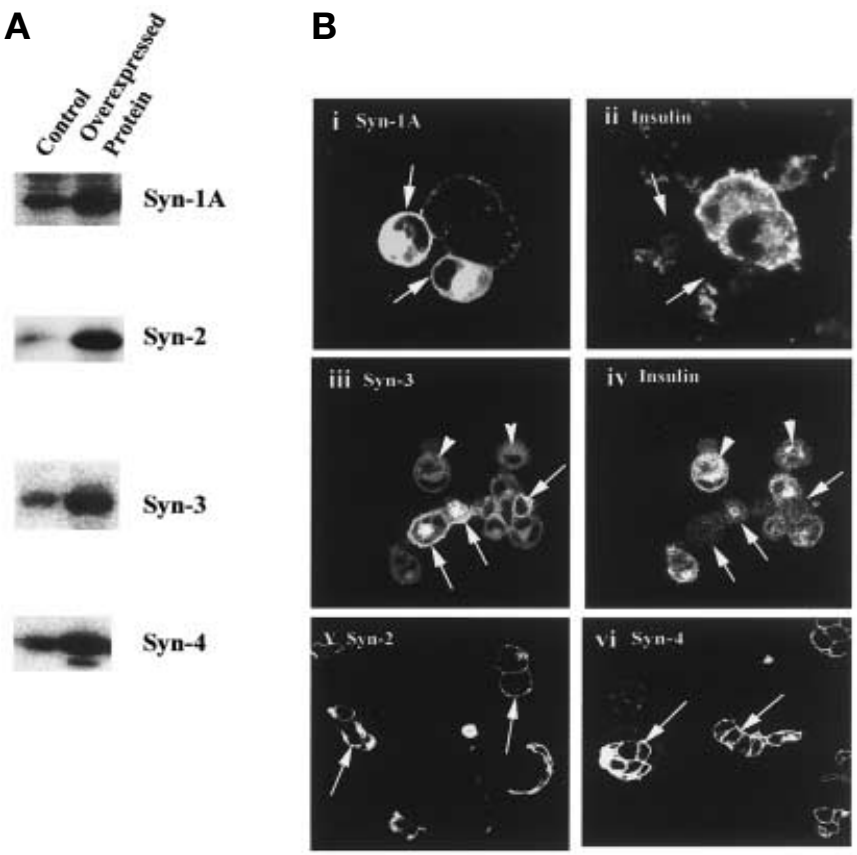

Fig.1 (A, B). Overexpression of Syntaxin-1A,- 2, -3 or -4 in HIT T-15 cells. (A) Immunoblot analysis of lysates (20 $\mu \mathrm{g}$ protein) of HIT-T15 cells overexpressing syntaxin- $-2,-3$ or -4 . Control HIT cells were transfected with the empty pcDNA3 vector. (B) Cellular localisation of the overexpressed syntaxins in HIT-T15 cells by confocal microscopy. Arrows point to the cells overexpressing the syntaxins (i, iii, v, and vi). Note that the insulin content of cells overexpressing Syn-1 or Syn-3 is reduced (ii and iv). Arrowheads point to the cytoplasmic location of Syn-3 (iii). The fluorescence gain intensity was reduced in order to better visualise the membrane localisation of the syntaxins; and therefore, the endogenous syntaxins signals of the untransfected cells appear weak

from HIT-T15 cells are shown in Fig. 2A. When the absolute amounts of insulin secreted into the media were compared, both overexpressed Syn-1 and -3 markedly inhibited high $\mathrm{K}^{+}$-induced insulin secretion by $49.7 \pm 5.5 \%$ and $49.1 \pm 6.2 \%(p<0.01)$, respectively (Fig. 2A). Taking into account the transfection efficiency of $40-50 \%$, this suggests that the secretion from the transfected cells is even more profoundly inhibited, which would be consistent with previous reports on the overexpression of Syn-1A in other insulinoma cell line $[13,15,36,37]$. Importantly, when we examined the total cellular insulin content of the Syn-1A and Syn-3 transfected cell lysates, we found that it was reduced by $24.8 \pm 4.2 \%(p<0.05)$ and $31.8 \pm 3.9 \% \quad(p<0.01)$, respectively (Fig. $2 \mathrm{~B})$. This suggests that the reduced insulin secretion could at least in part be contributed by a smaller amount of cellular insulin available for release. Overexpressed Syn- 2 and -4 had no effects on $\mathrm{K}^{+}$-induced insulin secretion and total cellular insulin.

Effects of syntaxins on endogenous insulin secretion in the single INS-1 cells. The cell population studies in
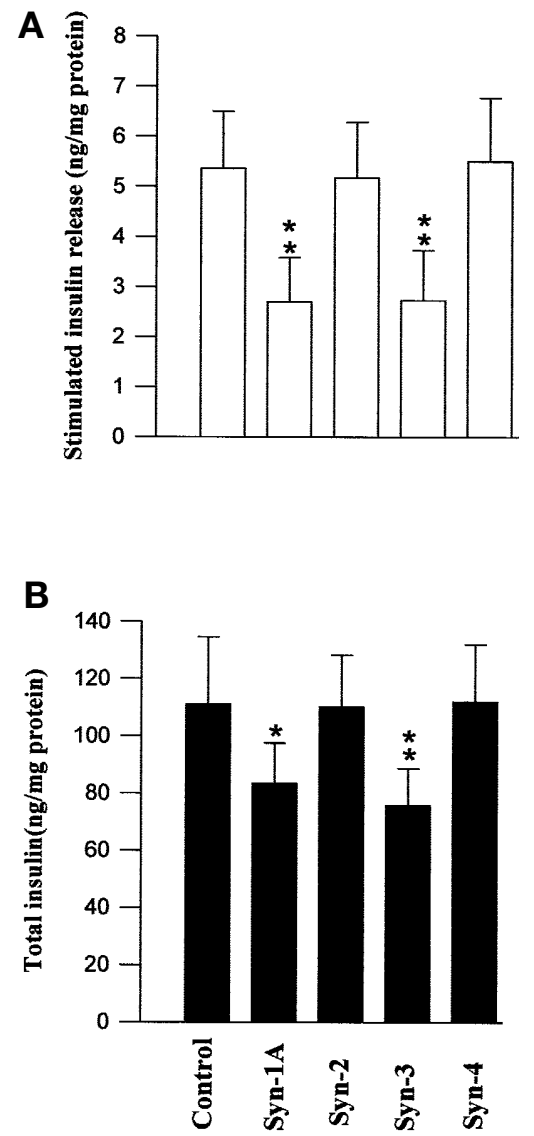

Fig. 2(A, B). The effects of overexpressed Syn-1A or -3 on endogenous insulin release. HIT T-15 cells transfected with Syn$1 A,-2,-3$, or -4 were stimulated with $30 \mathrm{mmol} / 1 \mathrm{KCI}$, and insulin released into the media determined. (A) Stimulated insulin released into the media above basal concentrations. (B) Total cellular insulin content remaining in the cells. The results are expressed as means \pm SEM of three separate experiments of four replicates per experiment. $* p<0.05 ; * * p<0.01$ compared with control

Figure $2 \mathrm{~A}$ and the variable transfection efficiency might not accurately reflect the full effects of the overexpressed syntaxins at the single beta-cell level. We therefore did capacitance measurements of voltage-induced membrane depolarization of INS-1 cells expressing recombinant Syn- $1 \mathrm{~A},-2,-3$, or -4 as shown in Figure 3. The INS-1 cell was depolarized from $-70 \mathrm{mV}$ (resting membrane potential) to $0 \mathrm{mV}$ to evoke maximal $\mathrm{Ca}^{2+}$ influx [32]. Like in $\mathrm{K}^{+}$-induced insulin secretion in HIT cells (Fig.2), both overexpressed Syn-1 and Syn-3 profoundly inhibited voltage-induced insulin secretion in INS-1 cells by $95.6 \%$ and $75.3 \%(p<0.01)$, respectively (Fig. 3A and B). The cells overexpressing Syn-2 and -4 showed insulin secretion similar to the control INS-1 cells. The absolute values of the capacitance changes are $68.0 \pm 21.0(n=9$ cells $), 3.3 \pm 3.3(n=6$ cells $)$, $58.0 \pm 13.2(n=5$ cells $), 16.5 \pm 4.8(n=11$ cells $)$, and $61.0 \pm 14.0(n=5$ cells $)$ for the control, Syn-1, $-2,-3$, -4 transfected INS-1 cells, respectively (Fig. 3B). 

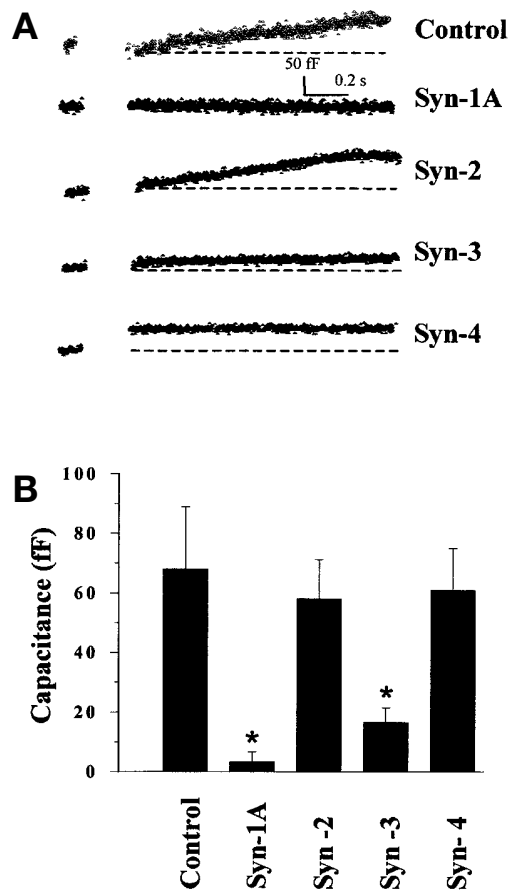

Fig.3(A, B). Distinct effects of Syn-1A, $-2,-3$ or -4 on voltage-induced insulin exocytosis. (A) Shows the representative traces of the membrane capacitance $\left(\mathrm{C}_{\mathrm{m}}\right)$ changes in control INS-1 cells, and cells transfected with $S y n-1 A,-2,-3$ or -4 . Cells were stimulated by a membrane depolarization from $-70 \mathrm{mV}$ to $0 \mathrm{mV}$, and the membrane capacitance $\left(\mathrm{C}_{\mathrm{m}}\right)$ increase was determined. Each trace consists of pre- and post-pulse $C_{m}$ values. $\mathrm{C}_{\mathrm{m}}$ increase is shown above a dotted line (base line) in the post-pulse trace. (B) shows the summary bar graph (means \pm SEM) of depolarization-stimulated $\mathrm{C}_{\mathrm{m}}$ increase in control ( $n=9$ cells), Syn-1A ( $n=6$ cells), Syn-2 $(n=5$ cells), Syn-3 $(n=11$ cells $)$ and Syn-4 $(n=5$ cells $)$ expressing cells. $* p<0.05$; compared with control

Effects of syntaxin overexpression on L-type $\mathrm{Ca}^{2+}$ channel activity. To examine whether changes to insulin release by syntaxin overexpression were mediated in part by alterations in L-type $\mathrm{Ca}^{2+}$ channel activity, we measured L-type $\mathrm{Ca}^{2+}$ currents in HIT-T15 cells using the patch clamp technique. We have previously shown that the majority of $\mathrm{Ca}^{2+}$ currents measured in these cells are L-type because more than $90 \%$ of the currents measured are inhibited by $10 \mu \mathrm{mol} / \mathrm{l}$ nifedipine [31]. HIT-T15 cells transfected with EGFP alone displayed robust L-type $\mathrm{Ca}^{2+}$ channels when using $\mathrm{Ba}^{2+}$ as the charge carrier. The L-type $\mathrm{Ca}^{2+}$ channels activated at $-40 \mathrm{mV}$ and peaked at $+10 \mathrm{mV}$ $(-14.1 \pm 1.7 \mathrm{pA} / \mathrm{pF}, n=10$; Fig. 4A, B) [31]. A $40-50 \%$ reduction in peak L-type $\mathrm{Ca}^{2+}$ channels at $+10 \mathrm{mV}$ was observed with Syn-1 $(-8.6 \pm 1.4 \mathrm{pA} /$ $\mathrm{pF}, n=13 ; p<0.05)$ or Syn-3 $(-6.7 \pm 0.9 \mathrm{pA} / \mathrm{pF}$, $n=13 ; p<0.01)$ overexpression but not with Syn-2 $(-15.9 \pm 3.6 \mathrm{pA} / \mathrm{pF})$ (Fig. 4B). Overexpression of the syntaxin isoforms did not affect the voltage dependence of channel activation or selectivity (Fig 4B).
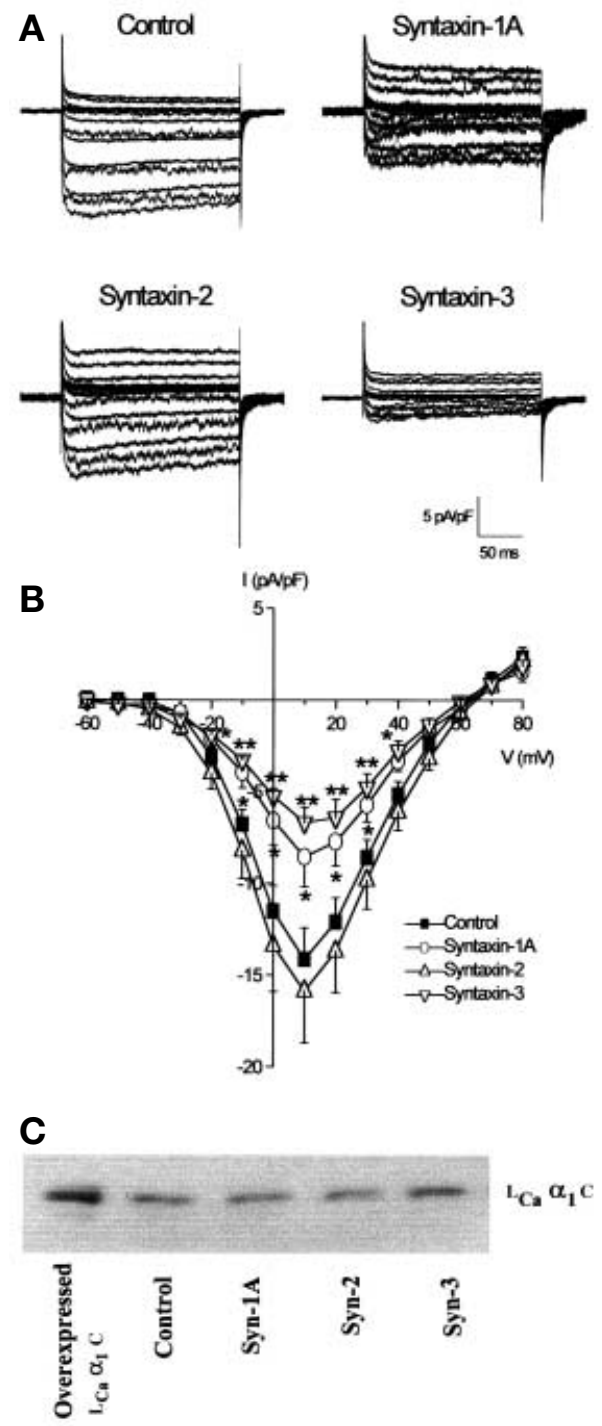

Fig. 4(A-C). Inhibition of L-type $\mathrm{Ca}^{2+}$ channel activity by Syn$1 \mathrm{~A}$ and -3 . HIT-T15 cells were transfected with $S y n-1 A,-2,-3$ or EGFP vector (control). Whole-cell $\mathrm{L}$-type $\mathrm{Ca}^{2+}$ channel activity was measured using $\mathrm{Ba}^{2+}$ as the charge carrier. (A) Ltype $\mathrm{Ca}^{2+}$ current traces from control, Syn-1A, -2 or -3 transfected cells. Cells were held at a holding potential of $-80 \mathrm{mV}$ and stepped from -60 to $+80 \mathrm{mV}$ in $10 \mathrm{mV}$ increments. (B) Summarised current-voltage relations from syntaxin overexpressing HIT cells. Currents were normalized to cell capacitance and plotted as means \pm SEM from 10 (control) or 13 (Syn-1A, -2 or -3 ) cells. $* p<0.05$, ** $p<0.01$ compared to control. (C) shows the lack of effect of the overexpressed Syntaxins on L-type $\mathrm{Ca}^{2+}$ channel $(\alpha 1 \mathrm{C})$ protein content in HIT cell lysates (25 $\mu$ g protein). Overexpressed L-type $\mathrm{Ca}^{2+}$ channel $\alpha_{1}$ $\mathrm{C}$ protein $(3.5 \mu \mathrm{g})$ is used as a positive control

Overexpression of Syn-1, $-2,-3$ or -4 did not significantly affect the basal concentrations of $\mathrm{Ca}^{2+}$ as determined by $\mathrm{Ca}^{2+}$ microfluorimetry (using Fura2AM) and digital imaging [30], and which were $70.8+3 \mathrm{nmol} / 1,67.9+4.9 \mathrm{nmol} / 1,60.2+6.7 \mathrm{nmol} / 1$, and $74.7+15.0 \mathrm{nmol} / \mathrm{l}$, respectively, compared to control concentrations of $69+1.8 \mathrm{nmol} / \mathrm{l}(n=6$ cells from 
two experiments for each, $p>0.05)$. Overexpression of these syntaxins had no effect on the cellular content of the L-type $\mathrm{Ca}^{2+}$ channel protein (Fig. 4C).

Effects of syntaxin overexpression on insulin gene transcription. The reduced total insulin content in cells overexpressing Syn-1 and Syn-3 (Figs. 1B and 2B) suggested an effect on insulin biosynthesis. We therefore examined insulin mRNA levels in cells overexpressing Syn-1A or -3 (Fig. 5). Both $18 \mathrm{~S}$ and 28S rRNA determination indicate equal loading of the samples (Fig. 5A). Northern blotting analysis showed that in the cells overexpressing Syn-1A or -3 , insulin mRNA concentrations were reduced by $24.5 \pm 2.5 \%$ and $25.7 \pm 4.2 \%(p<0.05)$, respectively (Fig. 5B), when compared to the control cells. Furthermore, these effects of Syn-1A and Syn-3 seem to be specific to the insulin-secretory protein rather than a generalised effect on protein synthesis. This is suggested by endogenous beta-actin content which was not affected (Fig. 5C). The reduction of insulin mRNA concentrations correlated with the lower cellular insulin content (Figs. 1B ii and iv and 2B).

We then examined whether the inhibition of insulin mRNA expression by Syn-1A and Syn-3 was at the transcription step, using a strategy similar to one previously reported [16]. Here, ECFP under the transcriptional control of the RIP2 promoter was used to examine the effects of syntaxins on reporter gene expression and the production of the ECFP. Given that heterologous cell lines are comprised of heterogeneous cells, with some not expressing insulin, this strategy provided a way to address this problem, because only cells with a beta-cell phenotype will express the translated gene product. Specifically, HITT15 cells were co-transfected with Syn-1A, -2, -3 or -4 along with RIP2-ECFP or ECFP empty vector (CMV promoter) as a control. The appearance of HIT cells overexpressing Syn-1A or -3 , but not Syn2 or -4 , indicated considerably less ECFP expressed under the transcriptional control of RIP2, but an almost equal amount of ECFP expressed under the control of CMV promoter (not shown). We quantitatively determined the effects of Syn- $1,-2,-3$ and -4 on the ECFP production by Western blot analysis. As shown in a representative blot in Figure 6A (middle panel), overexpressed Syn-1A or -3 greatly reduced ECFP content, whereas Syn- 2 or -4 had no such effects. The overexpression of Syn-1A or -3 had no effect on endogenous actin biosynthesis, which also served as the loading control. Densitometric analysis of the blots reveals that overexpessed Syn-1A or -3 markedly inhibited the production of ECFP under RIP2 transcriptional control by $53.3 \pm 9.1 \%$ and $39.0 \pm 6.8 \%(p<0.01)$, respectively (Fig. 6A). Similar results were obtained when RIP2d2EYFP (destabilised enhanced yellow fluorescent protein) was used for co-transfection. These results
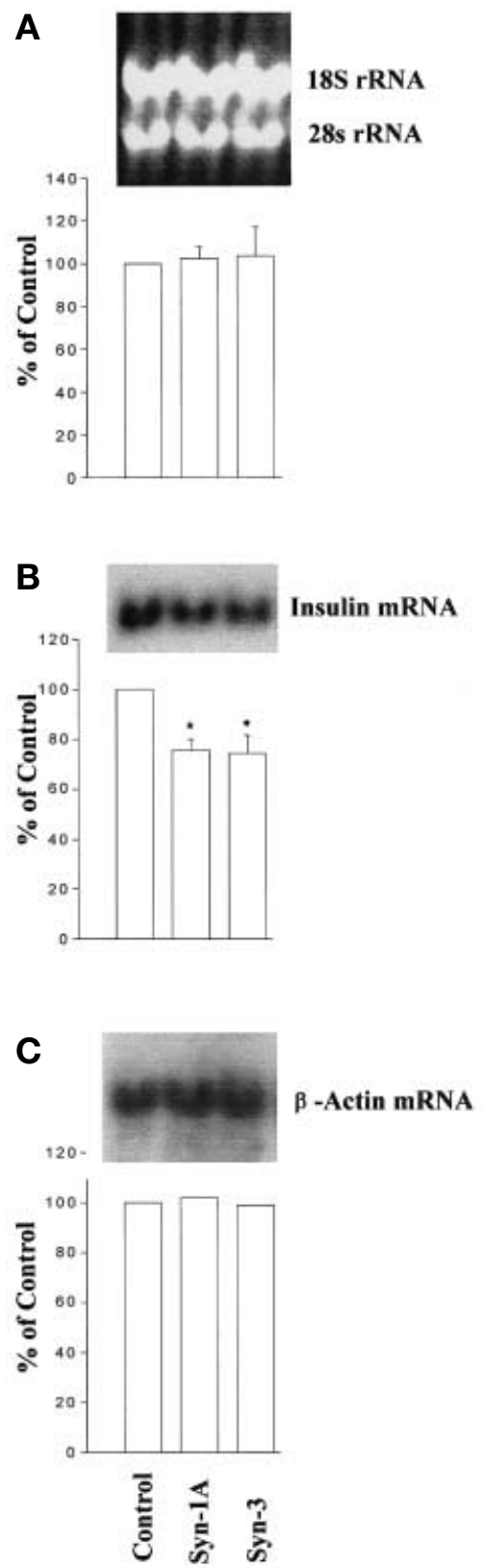

Fig.5(A-C). Reduction of endogenous insulin mRNA expression by Syn-1A or -3 expression in HIT T15 cells. HIT T15 cells were transfected with $S y n-1 A,-3$ or empty vector (Control). The total RNA was isolated from the transfected cells, electrophoresed ( $3 \mu \mathrm{g}$ RNA / lane) and transferred to nylon membranes, where the RNA was UV-crosslinked and hybridized to ${ }^{32} \mathrm{P}$-dCTP labelled probes. (A) shows the $18 \mathrm{~S}$ and $28 \mathrm{~S}$ ribosomal RNA to demonstrate equal RNA loading. (B) The blots were probed with insulin cDNA to determine insulin mRNA levels. (C) The same blots as in (B) were stripped and reprobed with human beta-actin cDNA. Below each of the representative blots shown is the quantitative densitometry of the specific bands from three separate experiments for (A) and (B), and the values (means \pm SEM.) are expressed as a percentage of the control in every experiment. Only one experiment was done for $(\mathbf{C}) .{ }^{*} p<0.05$ compared to control 
A
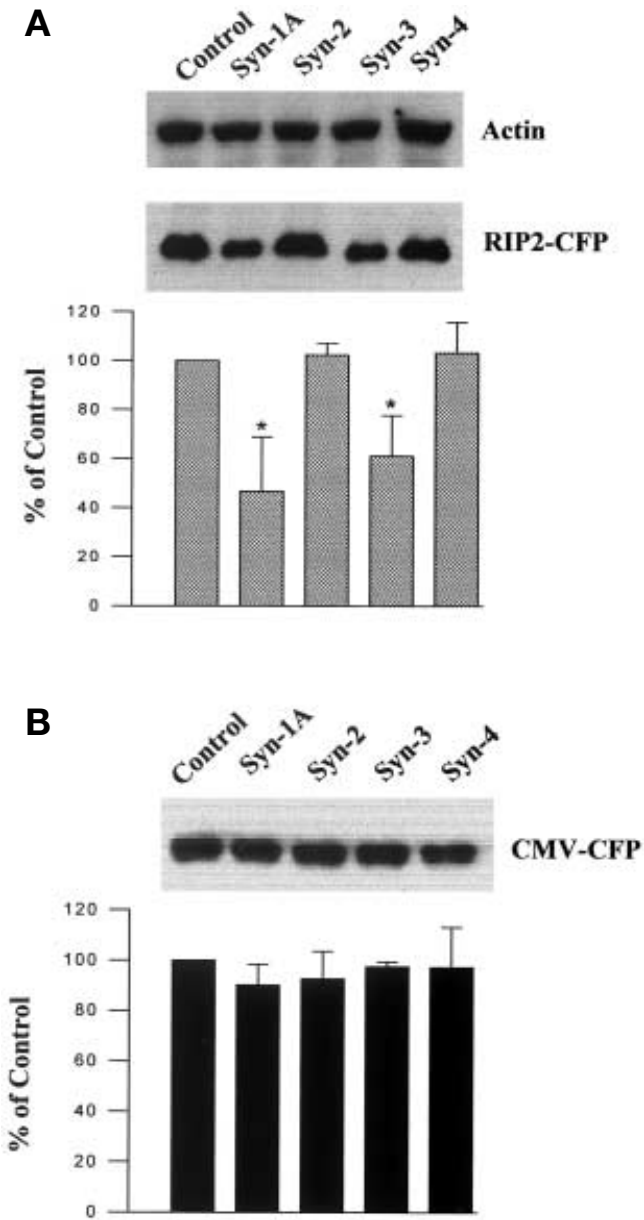

Fig. 6(A, B). Inhibition of insulin promoter activity by Syn-1A or -3 expression in HIT T15 cells. Western blot analysis of lysates $(20 \mu \mathrm{g}$ protein) of HIT-T15 cells co-transfected with Syn-1A, $-2,-3,-4$ or empty pcDNA 3 vector (control) together with RIP2-ECFP in (A) and CMV-ECFP in (B). (A) Upper panel, the equal actin content are shown as an endogenous control; middle panel, ECFP expressed under the transcriptional control of RIP2; lower panel, the ECFP specific bands from six separate experiments were quantified by densitometric scanning of the blots and summarised (means \pm SEM). (B) shows that Syn-1A, $-2,-3$, or -4 have no effect on ECFP production under the transcriptional control of the CMV promoter. Upper panel shows a representative blot and the lower panel is a summary of three separate experiments (means + SEM). $* p<0.01$ compared to control

showing Syn-1A and Syn-3 specific inhibition of RIP2-driven ECFP expression and not the CMVdriven identical protein (Fig. 6B), indicate that their inhibitory effects on insulin biosynthesis are at the level of insulin gene transcription.

\section{Discussion}

The inhibition of insulin secretion from either pancreatic islets or insulinoma cell lines overexpressing Syn-1A has been postulated to be due to an exocytot- ic blockade $[35,36]$. In this study we show that insulin biosynthesis is also inhibited by Syn-1A, suggesting that this inhibition probably contributes to reduced secretion. Our study showed a reduction of insulin biosynthesis and content in HIT cells overexpressing Syn-1 or Syn-3 at the steps of mRNA and insulin gene promoter activity, insulin protein content levels, and also at the single cell insulin content level as detected by confocal microscopy. In contrast, Syn-1A overexpression in another cell type, $\beta \mathrm{TC} 3$, increased insulin content [35]. Short-term glucose stimulation induced a parallel up regulation of Syn-1A expression and insulin biosynthesis in rat pancreatic islets at the translation step, and in insulinoma $\beta \mathrm{TC} 3$ cells at the level of transcription [36]. In contrast, longterm hyperglycaemia in a subtotal pancreatectomy rodent model, down regulated insulin gene transcription as a result of loss of islet differentiation [14]. Moreover, insulin itself can immediately regulate insulin gene transcription [17]. Overexpression of Syn$1 \mathrm{~A}$ in normal rat islets inhibited insulin secretion, whereas expression of Syn-1A in Syn-1A-reduced islets of diabetic GK rats restored insulin secretion [13]. The apparent discrepancy of Syn-1A actions in these studies suggests that Syn-1A plays a complex role of regulatory and feedback inhibitory actions on the insulin secretory processes, affecting not only exocytosis [35, 36], but also ion-channel function [7, $8]$, and in this study, insulin gene transcription and biosynthesis as well. Our study therefore suggests that chronic changes in Syn-1A concentrations, provide a distal loop, in addition to insulin, to regulate insulin gene transcription. A dysregulation of the expression of Syn-1A concentrations in obesity and Type-II diabetic rat models could activate or inhibit one or several of these processes to collectively alter insulin secretion $[12,13]$. Surprisingly, we show that these effects of Syn-1A, were mimicked by Syn-3 but were not observed with overexpression of other exocytic t-SNAREs, Syn-2 or Syn-4. Furthermore, these transcriptional effects specifically affected secretory proteins (insulin), and not general protein synthesis, as endogenous beta-actin and exogenous CMV-driven ECFP were not affected. In further support, Syn1A overexpression also did not affect glucose metabolism in $\beta$ TC3 cells [36].

Consistent with our findings is the report that GK rats islets contain reduced expression of Syn-1A but markedly increased proinsulin biosynthesis [13]. More interestingly, restoration of Syn-1A or SNAP25 expression in these GK rat islets partially restored glucose-induced insulin secretion [13]. We had reported that in $f a / f a$ Zucker rats, VAMP-2 and SNAP-25 expression were also reduced along with Syn-1A, and this was associated with basal hyperinsulinaemia and reduced high-glucose-induced insulin secretion [12]. It has been postulated that the increases in proinsulin biosynthesis could be a response to 
accelerated insulin degradation [13]. Our alternative explanation would be that Syn-1A inhibits proinsulin biosynthesis at the transcription step. Nonetheless, these studies taken together indicate that Syn-1A is a key protein which maintains a balance between the biosynthesis and secretion. In contrast to our results with beta-cell lines which possess both constitutive and regulated secretory pathways, co-expression of Syn-1A and human growth hormone in the constitutive COS-cell model resulted in an increase in storage of growth hormone in vesicles and decreased constitutive release, which together increased cellulargrowth hormone content [37]. COS cells possess only constitutive pathways, and do not express endogenous Syn-1A or secretory proteins (growth hormone). This discrepancy suggests that Syn-1A has preferential actions depending on the cell types and their predominant secretory pathways. Such diverse and sometimes contradictory actions of Syn-1A could also in part be explained by Syn-1A binding to a large and increasing number of proteins which mediate distinct cellular actions [18, 19, 38]. An inappropriate stoichiometry between Syn-1A and these proteins would therefore be expected to alter these cellular processes.

Our report shows that a syntaxin (Syn-3) other than Syn-1A has profound effects on the insulin secretory process. Whereas the structure-function of Syn-1A is becoming more clear [18, 38], little is known about the structure-function of the other syntaxins $[10,21]$. The presumed functions of these syntaxins have been deduced from their structural similarities to Syn-1A. Indeed, the striking similarity of the effects of Syn-1A and Syn-3 in the inhibition of insulin biosynthesis, $\mathrm{K}^{+}$-induced insulin secretion and L-type $\mathrm{Ca}^{2+}$ channels strongly suggests that these effects could be mediated by analogous functional domains within these proteins [21], and also, that similar associated proteins exist which bind these domains. Syn-3 shares $64 \%$ of the same amino acid structure as Syn-1A [21] and the coiled coil domains which bind many proteins are conserved in these syntaxins $[18,39]$. Both syntaxins bind SNAP-25 and VAMP-2 to form stable complexes [39, 40], and also Munc18 a and Munc18b, which blocked the formation of these complexes [41]. Both syntaxins could be cleaved by botulinum neurotoxin $\mathrm{C}$, although Syn-3 is somewhat resistant to proteolytic cleavage [42]. There are, however, some differences between Syn-3 and Syn-1A. They are in distinct cellular locations in epithelial cells [21, 24, 45]. Whereas HIT and islet beta cells contain both syntaxins [26], non-neuronal cells more often contain abundant Syn-3 (and Syn-2 and Syn-4) but Syn-1 was undetectable [24, 25, $43,44]$. Syn-3 was also present in the cytoplasm of the HITcells which overlaps with the insulin labelling. This is similar to the Syn-3 location on zymogen granules of pancreatic acinar cells $[24,45]$ and tubulovesi- cles of gastric parietal cells [43]. In acinar cells, Syn-3 is thought to play a role in homotypic secretory granule fusion $[24,45,46]$, which is part of the process of compound exocytosis. Syn-3 might play a similar role in islet beta cells in lieu of the recent study showing that compound exocytosis also occurs in islet beta cells [47]. This is also supported by our study showing that overexpression of Syn-3 inhibits insulin exocytosis, as demonstrated by capacitance measurements. However, it would be difficult to precisely determine this action of Syn-3 in the present study because of the inhibition on insulin biosynthesis. In MDCK cells [24] and hepatocytes [44], Syn-3 is more abundant on apical plasma membranes. In these non-neuronal cells, Syn-3 is thought to be the putative syntaxin mediating apical exocytosis. This apical membrane targeting in epithelial cells [48] shows similarities with axonal protein targeting in neurons. By showing similar inhibitory effects of Syn-1A and Syn-3 on $\mathrm{Ca}^{2+}$ induced insulin secretion and L-type $\mathrm{Ca}^{2+}$ channel current, our data suggest that Syn-3 in non-neuronal cells could serve some functions of neuronal Syn-1A. Surprisingly, Syn-3 also has similar actions as Syn-1 in inhibiting insulin gene transcription and biosynthesis in HIT cells. Syn-3 could therefore have a similar effect on the synthesis of secretory proteins in non-neuronal cells. Interestingly, Syn-2, which also shares a high homology ( $>60 \%$ amino acid identity) to Syn-1A and Syn-3 [21], and binds some similar proteins $[39,40]$, did not mimic these Syn-1A or Syn-3 actions on HIT cells, nor Syn-1A and Syn-3 actions on $\mathrm{Ca}^{2+}$ channels $[7,8]$ (Fig.4) in this study. The redundant effects of Syn-1A and Syn3 in insulin secreting beta cells follow the same theme of VAMP [28] and SNAP-25 proteins [29]. The overlapping function of Syn-3 on insulin secretion can now in part also be explained by an inhibitory action on the L-type $\mathrm{Ca}^{2+}$ channel (Fig. 4).

Taken together, our results show that the SNARE protein syntaxins could mediate an additional new action on the insulin secretory process which is insulin gene transcription. Furthermore, Syn-3 is capable of mimicking the cellular actions of Syn-1A, including insulin biosynthesis, insulin exocytotic fusion processes and L-type $\mathrm{Ca}^{2+}$ channel inhibition, probably by similar mechanisms. Further studies are required to identify the functional significance of Syn-2 and Syn-4 in islet beta cells.

Acknowledgements. We thank W. Trimble for reviewing this manuscript and G. Wang, Z. Sun, and L. Sheu for technical assistance. This work is supported by grants from the Canadian Diabetes Association, Juvenile Diabetes Foundation and $\mathrm{Na}$ tional Institutes of Health - DK55160 to H.Y.G., and also grants from the Canadian Institute for Health Research to M.B.Wheeler (MOP-12898) and to R.G.Tsushima (MT 36498). H. Gaisano is a recipient of the American Gastroenterology Association/ Industry (Pharmacia and Upjohn) Research Scholar Award. 


\section{References}

1. Wollheim CB, Lang J, Regazzi R (1996) The exocytotic process of insulin secretion and its regulation by $\mathrm{Ca}^{2+}$ and G-proteins. Diabetes Rev 4: 276-397

2. Sudhof TC (1995) The synaptic vesicle cycle: a cascade of protein-protein interactions. Nature 375: 645-653

3. Weber T, Zemelman BV, McNew JA et al. (1998) SNAREpins: minimal machinery for membrane fusion. Cell 92: 759-772

4. Daniel S, Noda M, Straub SG, Sharp GWG (1999) Identification of the docked granule pool responsible for the first phase of glucose-stimulated insulin secretion. Diabetes 48: 1686-1690

5. Salem N, Aundez V, Horng J-T, Kelly RB (1998) A vSNARE participates in synaptic vesicle formation mediated by the AP3 adaptor complex. Nat Neurosci 1: $551-556$

6. Sheng ZH, Rettig J, Cook T, Catterall WA (1996) $\mathrm{Ca}^{2+}$-dependent interaction of $\mathrm{N}$-type $\mathrm{Ca}^{2+}$ channels with the core complex. Nature 379: 451-454

7. Wiser O, Bennett MK, Atlas D (1996) Functional interaction of syntaxin and SNAP-25 with voltage-sensitive Land N-type $\mathrm{Ca}^{2+}$ channels. EMBO J 15: 4100-4110

8. Yang S-N, Larsson O, Bränström R et al. (1999) Syntaxin interacts with the $\mathrm{L}_{\mathrm{D}}$ subtype of voltage-gated $\mathrm{Ca}^{2+}$ channels in pancreatic $\beta$-cells. Proc Natl Acad Sci USA 96: 10164-10169

9. Osen-Sand A, Catsicas M, Staple JK et al. (1993) Inhibition of axonal growth by SNAP-25 antisense oligonucleotides in vitro and in vivo. Nature 364: 20353-30358

10. Linial M (1997) SNARE proteins-why so many, why so few? J Neurochem 69: 1781-1792

11. Leahy JL (1990) Natural history of beta cell dysfunction in NIDDM. Diabetes Care 13: 992-1010

12. Chan CB, MacPhail RM, Sheu L, Wheeler M, Gaisano $\mathrm{HY}(1999)$ Beta cell hypertrophy in fa/fa rats is associated with basal glucose hypersensitivity and reduced SNARE protein expression. Diabetes 48: 997-1005

13. Nagamatsu S, Nakamichi Y, Yamamura C et al. (1999) Decreased expression of t-SNARE, syntaxin-1 and SNAP-25 in pancreatic beta cells is involved in impaired insulin secretion from diabetic GK rat islets, restoration of decreased t-SNARE proteins improves impaired insulin secretion. Diabetes 48: 2367-3373

14. Jonas J-C, Sharma A, Hasenkamp W et al. (1999) Chronic hyperglycemia triggers loss of pancreatic $\beta$-cell differentiation in an animal model of diabetes. J Biol Chem 274: 14112-14121

15. Nagamatsu S, Nakamichi Y, Katahira H (1997) Syntaxin, but not SNAP biosynthesis by rat pancreatic islets is regulated by glucose in parallel with proinsulin biosynthesis. Diabetologia 40: 1396-1402

16. Leibiger B, Moede T, Schwarz T et al. (1998) Short-term regulation of insulin gene transcription by glucose. Proc Natl Acad Sci USA 95: 9307-9312

17. Leibiger B, Wahlander K, Berggren P-O, Leibiger IB (2000) Glucose-stimulated insulin biosynthesis depends on insulin-stimulated gene transcription. J Biol Chem 275: 30153-30156

18. Wu MN, Fergestad T, Lloyd TE, He Y, Broadie K, Bellen H J (1999) Syntaxin 1A interacts with multiple exocytic proteins to regulate neurotransmitter release in vivo. Neuron 23: 593605

19. Betz A, Okamaot M, Bensler F, Brose A (1997) Direct interaction of the rat unc13 homolog munc13-1 with the $\mathrm{N}$ terminus of syntaxin. J Biol Chem 272: 2520-3526
20. Naren AP, DJ Nelson, Xie W et al. (1997) Regulation of CFTR chloride channels by syntaxin and Munc18 isoforms. Nature 390: 302-305

21. Bennett MK, Garcia-Arrarás JE, Elferink LA et al. (1993) The syntaxin family of vesicular transport receptors. Cell 74: 863-873

22. Volchuk A, Wang Q, Ewart HS et al. (1996) Syntaxin 4 in 3T3-L1 adipocytes: regulation by insulin and participation in insulin-dependent glucose transport. Mol Biol Cell 7: 1075-1082

23. Olson AL, Knight JB, Pessin JE (1997) Syntaxin 4, VAMP2 , and /or VAMP-3 are functional $\mathrm{t}$ - and v-SNAREs for insulin-stimulated GLUT4 translocation in adipocytes. Mol Cell Biol 17: 2425-3435

24. Gaisano HY, Ghai M, Sheu L, Bouquillon A, Bennett MK, Trimble WS (1996) Distinct locations of the syntaxin family of proteins in rat pancreatic acinar cells. Mol Biol Cell 7: 2019-3027

25. Low HS, Chapin JS, Weimbs T, Komuves LG, Bennett MK, Mostov KE (1996) Differential localization of syntaxin isoforms in polarized MDCK cells. Mol Biol Cell 7: 2007-3018

26. Wheeler MB, Sheu L, Ghai M et al. (1996) Characterization of SNARE protein expression in $\beta$-cell lines and pancreatic islets. Endocrinology 137: 1340-1348

27. Jacobsson G, Bean AJ, Scheller RH et al. (1994) Identification of synaptic proteins and their isoform mRNAs in compartments of pancreatic endocrine cells. Proc Natl Acad Sci USA 91: 12487-12491

28. Regazzi R, Sadoul K, Meda P, Kelly RB, HalbanPA, Wollheim CB (1996) Mutational analysis of VAMP domain implicated in $\mathrm{Ca}^{2+}$-induced insulin exocytosis. EMBO J 15: 6951-6959

29. Sadoul K, Berger A, Niemann H et al. (1997) SNAP-23 is not cleaved by botulinum neurotoxin $\mathrm{E}$ and can replace SNAP-25 in the process of insulin secretion. J Biol Chem 272: 33033-33027

30. Huang X, Wheeler MB, Kang Y et al. (1998) Truncated SNAP-25 (1-197), like Botulinum neurotoxin A, can inhibit insulin secretion from HIT-T15 insulinoma cells. Mol Endocrinol 12: 1060-1070

31. Salapatek, AM, MacDonald P, Gaisano HY, Wheeler MB (1999) Mutations to the third cytoplasmic domain of GLP1 receptor can functionally uncoupled from GLP-1 stimulated insulin secretion in HIT-T15 cells. Mol Endocrinol 13: $1305-1317$

32. Huang X, Kang Y-H, Pasyk EA, Sheu L, Salapatek A, Gaisano HY (2001) $\mathrm{Ca}^{2+}$ influx and cAMP elevation overcame botulinum toxin $\mathrm{A}$ but not tetanus toxin inhibition of insulin exocytosis. Amer J Physiol Cell Physiol 281: C740-C750

33. Renstrom E, Eliasson L, Rorsman P (1997) Protein kinase A-dependent and -independent stimulation of exocytosis by cAMP in mouse pancreatic $\beta$ cells. J Physiol (Lond) 502: 105-118

34. Hamill OP, Marty A, Neher E, Sakmann B, Sigworth FJ (1981) Improved patch-clamp techniques for high-resolution current recording from cells and cell-free membrane patches. Pflugers Arch 391: 85-100

35. Nagamatsu S, Fujiwara T, Nakamichi Y et al. (1996) Expression and functional role of syntaxin $1 / \mathrm{HPC}-1$ in pancreatic $\beta$-cells. J Biol Chem 271: 1160-1165

36. Nagamatsu S, Nakamichi Y, Yamaguchi K, Sawa H, Akagawa K (1997) Overexpressed syntaxin 1A/HPC-1 inhibits insulin secretion via a regulated pathway, but does not influence glucose metabolism and intracellular $\mathrm{Ca}^{2+}$ in insulinoma cell line $\beta \mathrm{TC} 3$ cells. Biochem. Biophys Res Commun 231: 89-93 
37. Bittner MA, Bennett MK, Holz RW (1996) Evidence that syntaxin 1A is involved in storage in the secretory pathway. J Biol Chem 271: 11214-11221

38. Dulubova I, Sugita S, Hill S et al. (1999) A conformational switch in syntaxin during exocytosis: role of Munc18. EMBO J 18: 4372-4382

39. Calakos N, Bennett MK, Peterson KE, Scheller RH (1994) Protein-protein interactions contributing to the specificity of intracellullar vesicular trafficking. Science 263: 1146-1149

40. Fasshauer D, Antonin W, Margittai M, Pabst S, Jahn R (1999) Mixed and non-cognate SNARE complexes- characterization of assembly and biophysical properties. J Biol Chem 274: 15440-15446

41. Tellam JT, Macaulay SL, McIntosh A, Hewish DR, Ward CW, James DE (1997) Characterization of Munc18c and syntaxin 4 in 3T3-L1 adipocytes J Biol Chem 272: 6179-6181

42. Schiavo G, Shone CC, Bennett MK, Scheller RH, Monteccuco C (1995) Botulinum neurotoxin C cleaves a single Lys-Ala bond within the C-terminal regions of syntaxins. J Biol Chem 270: 10566-10570
43. Peng XR, Yao X, Chow DC, Forte JG, Bennett MK (1997) Association of syntaxin 3 and VAMP with $\mathrm{H}^{+} / \mathrm{K}^{+}$-ATPase containing tubulovesicles in gastric parietal cells. Mol Biol Cell 8: 399-407

44. Fujita H, Tuma PL, Finnegan CM, Locco L, Hubbard AL (1998) Endogenous syntaxins 2, 3 and 4 exhibit distinct but overlapping patterns of expression at the hepatocyte plasma membrane. Biochem J 329: 527-538

45. Hansen HJ, Antonin W, Edwardson JM (1999) Identification of SNAREs involved in regulated exocytosis in the pancreatic acinar cells. J Biol Chem 274: 22871-32876

46. Gaisano HY (2000) A hypothesis: SNARE-ing the mechanisms of regulated exocytosis and pathologic membrane fusions in the pancreatic acinar cell. Pancreas 20: 217-326

47. Bokvist K, Holmqvist M, Gromada J, Rorsman P (2000) Compound exocytosis in voltage-clamped mouse pancreatic b-cells revealed by carbon fibre amperometry. Pflugers Arch 439: 634-645

48. Dotti CG, Simons K (1990) Polarized sorting of viral glycoproteins to the axon and dendrites of hippocampal neurons in culture. Cell 62: 63-72 